\title{
The effect of ball-milling on the dispersion of carbon nanotubes: the electrical conductivity of carbon nanotubes-incorporated $\mathrm{ZnO}$
}

\author{
Tae-Won LEE, Chang-Sun PARK and Hyung-Ho PARK ${ }^{\dagger}$ \\ Department of Materials Science and Engineering, Yonsei University, Seoul 120-749, Korea
}

\begin{abstract}
Nowadays a lot of studies were conducted to improve electronic properties of $\mathrm{ZnO}$ for transparent conducting oxide materials using single-wall carbon nanotube (SWCNT). In this study, ZnO nanocomposite films containing 0.1 wt \% of SWCNTs were synthesized using a sol-gel method. Variation in ball-milling time of SWCNTs up to $12 \mathrm{~h}$ was introduced to induce a difference in the distribution size and length of SWCNTs. The ball-milling effect was analyzed with scanning electron microscopic studies and electrical property measurement of SWCNTs-incorporated ZnO nanocomposite films. Dispersion and shortening of SWCNTs were observed with increasing ball-milling time: dispersion was saturated but shortening was proceeded. $9 \mathrm{~h}$ of ball-milling time was found to optimize dispersion and shortening of SWCNTs, confirmed from the electrical property measurement. With optimized ball-milling time of $9 \mathrm{~h}$, a transmittance in the visible light range of SWCNTs-incorporated $\mathrm{ZnO}$ film maintained over $87 \%$ of transparency. Also the resistivity of this film $(0.53 \Omega \mathrm{cm})$ was less than that $(1.48 \Omega \mathrm{cm})$ of SWCNTs-incorporating ZnO without a ball-milling.
\end{abstract}

C2014 The Ceramic Society of Japan. All rights reserved.

Key-words : ZnO, SWCNTs, Ball-milling, Dispersion, Shortening, Electrical property

[Received February 16, 2014; Accepted June 11, 2014]

\section{Introduction}

The study of transparent conducting oxides (TCOs) has actively progressed in part of optoelectronics and photovoltaic devices including liquid crystal display, flat-panel display, organic lightemitting display, light-sensor, organic-solar-battery, and so on due to their excellent light transmittance and high electrical conductivity. ${ }^{1), 2)}$ Among them, indium tin oxide (ITO) has many advantages such as high electrical conductivity, wide band gap $(3.5-4.3 \mathrm{eV})$, great light transmittance, chemical stability, etc. ${ }^{3)-5)}$ However, ITO has problems, for example, an expensive price and natural depletion. $\left.{ }^{6}\right)$ A lot of researchers have been studying the conducting oxides such as $\mathrm{ZnO}$ and $\mathrm{SnO}_{2}$ to substitute ITO. ${ }^{7,8)}$ Among these oxides, $\mathrm{ZnO}$ has wide band gap $(3.3 \mathrm{eV})$ as n-type semiconductor and shows many merits like transparency, chemical stability, nontoxic and cheap price. ${ }^{9)}$ But $\mathrm{ZnO}$ has a problem of low electrical conductivity compared to ITO for application to TCO. To solve this problem, a lot of studies of doping have been actively investigated using trivalent metal cation such as $\mathrm{Al}, \mathrm{Ga}$, and $\mathrm{B}$, and halogen anion such as $\mathrm{F}$ and $\mathrm{Cl}^{10)-14)}$ Among the studies to improve the electrical property, many studies were progressed using single-wall carbon nanotubes (SWCNTs) and graphene for improvement of the electrical property of $\mathrm{ZnO}{ }^{15), 16)}$ Especially, SWCNT is carbonbased 1 dimensional nanostructured material and shows superior properties such as electrical conductivity, mechanical hardness, and chemical stability. ${ }^{17)}$ Because the electrical conductivity could be increased with small amount incorporation of SWCNT while maintaining the optical transparency, SWCNT is considered to be suitable material for a reinforcement of TCO. ${ }^{18)}$ However a distribution of SWCNTs was very difficult because SWCNTs maintain an agglomerated structure followed by van

Corresponding author: H.-H. Park; E-mail: hhpark@yonsei.ac.kr * Preface for this article: Dol http://dx.doi.org/10.2109/jcersj2.122.P8-1 der Waals interaction between nanotubes. ${ }^{19)}$ To overcome this problem, a study on the distribution of SWCNT has been progressed. ${ }^{20)}$ Among the various dispersion methods, ball-milling was representative mechanical distribution and known for narrowing size and diameter distribution. ${ }^{21)-25)}$ If the optimized SWCNTs were incorporated into $\mathrm{ZnO}$, the electrical property of $\mathrm{ZnO}$ would be maximized. In this study, sol-gel and ball-milling method were used to synthesize $\mathrm{ZnO}$ nanocomposite films containing SWCNTs. The effect of ball-milling time on the dispersion and length of SWCNTs was investigated to optimize a dispersion degree in order to get an enhanced electrical and optical properties of $\mathrm{ZnO}$ material.

\section{Experimental procedure}

$\mathrm{ZnO}$ thin films were prepared by sol-gel process. Zinc acetate dihydrate $\left[\mathrm{Zn}\left(\mathrm{CH}_{3} \mathrm{COO}\right)_{2} 2 \mathrm{H}_{2} \mathrm{O}\right]$, 2-methoxyethanol, and monoethanolamine (MEA) were used as $\mathrm{Zn}$ precursor, solvent, and sol stabilizer, respectively. After 2-methoxyethanol and MEA were mixed by stirring, zinc acetate dihydrate was dissolved in the solution at room temperature. SWCNTs (ASA-100F, Hanhwa Nanotech) were ball-milled for 3, 6, 9, and $12 \mathrm{~h}$ each and mixed with ethanol to be centrifuged at 20,000 rpm to purify SWCNTs. After centrifuging, about $80 \%$ of the solution mixture from the top was taken excluding bottom part of the solution containing catalyst and amorphous carbon, and dried in an oven at $60^{\circ} \mathrm{C}$ for $1 \mathrm{~h}$ to remove ethanol. $0.1 \mathrm{wt} \%$ ball-milled SWCNT was incorporated into $\mathrm{ZnO}$ solution. The concentration of zinc acetate dihydrate was $0.5 \mathrm{M}$. The mixed solution was stirred at room temperature for $5 \mathrm{~h}$ and then spin-coated immediately on glass (Corning 1737) substrate at $2000 \mathrm{rpm}$ for $20 \mathrm{~s}$. Spin-coating and drying procedure were repeated for two times to obtain a desired thickness of $70 \mathrm{~nm}$. The films were annealed in a tube furnace under $\mathrm{N}_{2}$ atmosphere at $500^{\circ} \mathrm{C}$ for $1 \mathrm{~h}$. The agglomeration of SWCNTs was characterized by using a field emission scanning electron microscopy (FE-SEM; JEOL, JSM 7001F). The crys- 
tallinity of SWCNTs-incorporated $\mathrm{ZnO}$ films was analyzed by using X-ray diffractometer (XRD; D/MAX-2000, Rigaku) with $\mathrm{CuK} \alpha$ radiation $(\lambda=1.5418 \AA)$. The resistivity, carrier concentration, and carrier mobility of the films were measured by using Hall effect measurement system (HMS-3000, Ecopia). Optical transmittance measurements were performed using an ultraviolet-visible-near infrared (UV-vis-NIR, V-570, Jasco) spectrophotometer.

\section{Results and discussions}

Dispersity of SWCNTs according to ball-milling time was investigated by SEM analysis. All SWCNTs powder samples were centrifuged to be purified after ball-milling. As shown in Fig. 1, SWCNT aggregates got smaller with increasing ballmilling time and the length reduced at the same time. In general when SWCNT was added to matrix materials, the SWCNT needs very high aspect ratio to form a percolation network to increase the electrical conductivity. ${ }^{26)}$ However as shown in Fig. 1(a), pre ball-milled SWCNT seemed to be severely entangled due to aggregated bundle not to be expected to increase huge electrical conductivity. ${ }^{27)}$ Such property can be seen easily in short SWCNT which has low electrical conductivity due to relatively low aspect ratio. ${ }^{28)}$ However as ball-milling progresses, a fine mesh structure was formed entirely and size of SWCNT aggregates decrease as shown in Figs. 1(b) to 1(d). Such structure is known as transferring something to any direction effectively like shape of vein in human's body. ${ }^{29)}$ In contrast, SWCNT was destroyed by $12 \mathrm{~h}$ of ball-milling, length reduction induced very low aspect ratio as shown in Fig. 1(e). The size of SWCNTs agglomerate was estimated from the measured distribution area of SWCNTs aggregates in the SEM images as shown as corresponded area with yellow lines in Fig. 1. Four typical SEM images of each 5 different kind of samples (different ball-milling time), total 20 SEM images were used to measure the distribution area of SWCNTs aggregates. The average distribution area of SWCNTs aggregates depending on ball-milling time was given at upper right side in the figure. The average size of SWCNTs agglomerates reduced as ball-milling time increased. The SWCNT-incorporated $\mathrm{ZnO}$ thin films were synthesized by solgel process adding differently dispersed SWCNTs as described above. XRD patterns of SWCNT-incorporated $\mathrm{ZnO}$ films were analyzed to investigate $\mathrm{ZnO}$ phase formation, crystallization change by an addition of SWCNT. As shown in Fig. 2, the diffraction peaks of all samples at $2 \theta$ angles of $31.8,34.5$, and $36.3^{\circ}$ were indexed as 100,002 , and 101 , respectively with a hexagonal wurzite structure of $\mathrm{ZnO} .^{30)}$ Also peak shift or intensity changes in main were not found in all samples. With these results, any changes in crystal structure or crystallinity of $\mathrm{ZnO}$ were not found by incorporation of SWCNT. In Fig. 3, UV-vis absorption spectra of SWCNT-incorporated $\mathrm{ZnO}$ films were shown to analyze the optical properties of SWCNTs according to dispersity. All samples show over $87 \%$ transmittance in visible

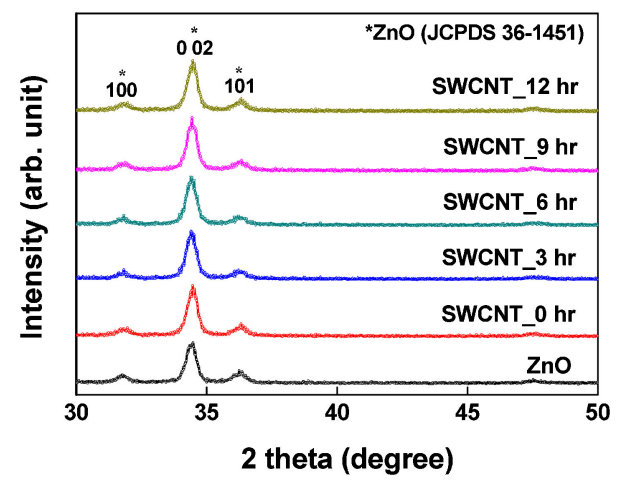

Fig. 2. XRD patterns of SWCNT-incorporated $\mathrm{ZnO}$ thin films according to various ball-milling time.

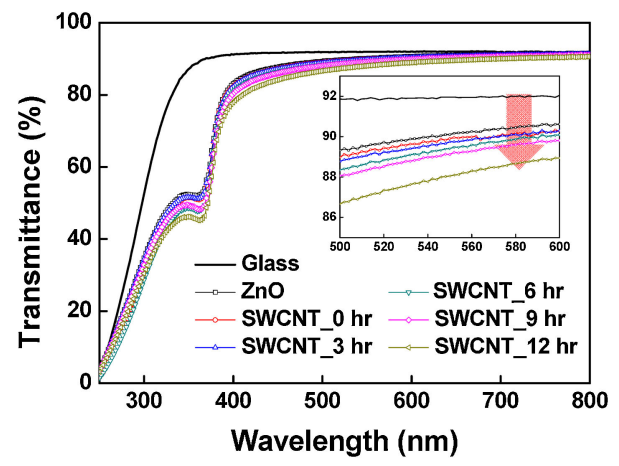

Fig. 3. Optical transmittance of SWCNT-incorporated $\mathrm{ZnO}$ thin films according to various ball-milling time.
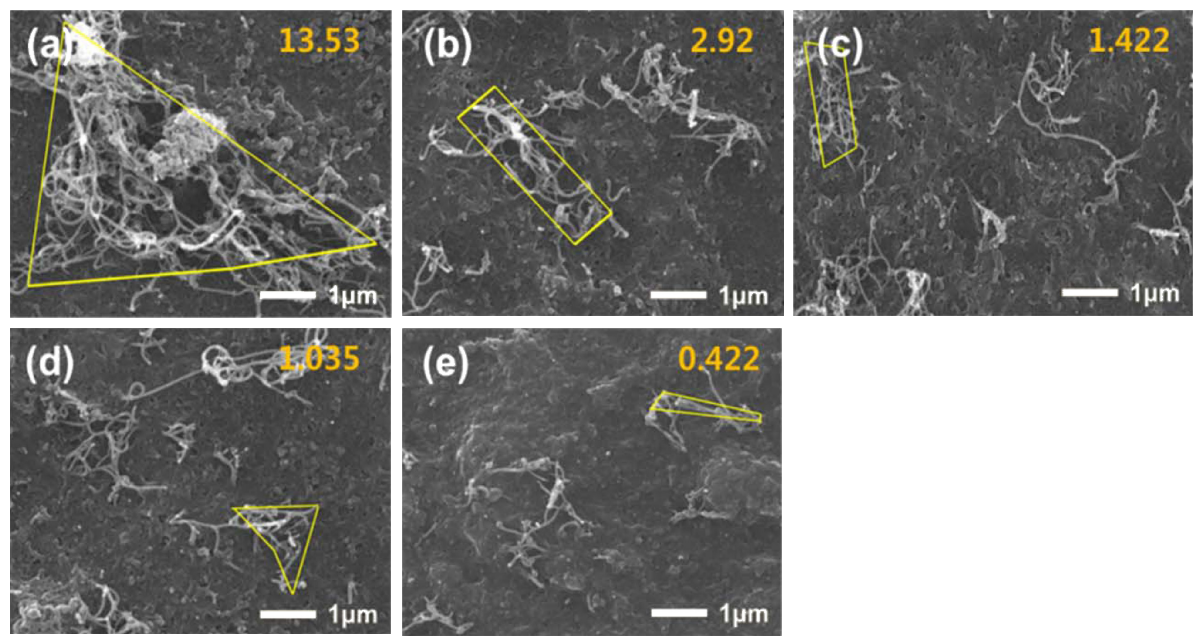

Fig. 1. SEM images of SWCNTs on carbon tape according to various ball-milling time: (a) before, (b) $3 \mathrm{~h}$, (c) $6 \mathrm{~h}$, (d) $9 \mathrm{~h}$, and (e) $12 \mathrm{~h}$. The numbers on upper right side is average measurement size of agglomerates of SWCNTs. Before attached on carbon tapes, all SWCNTs samples were centrifuged after ball-milling to be purified. 

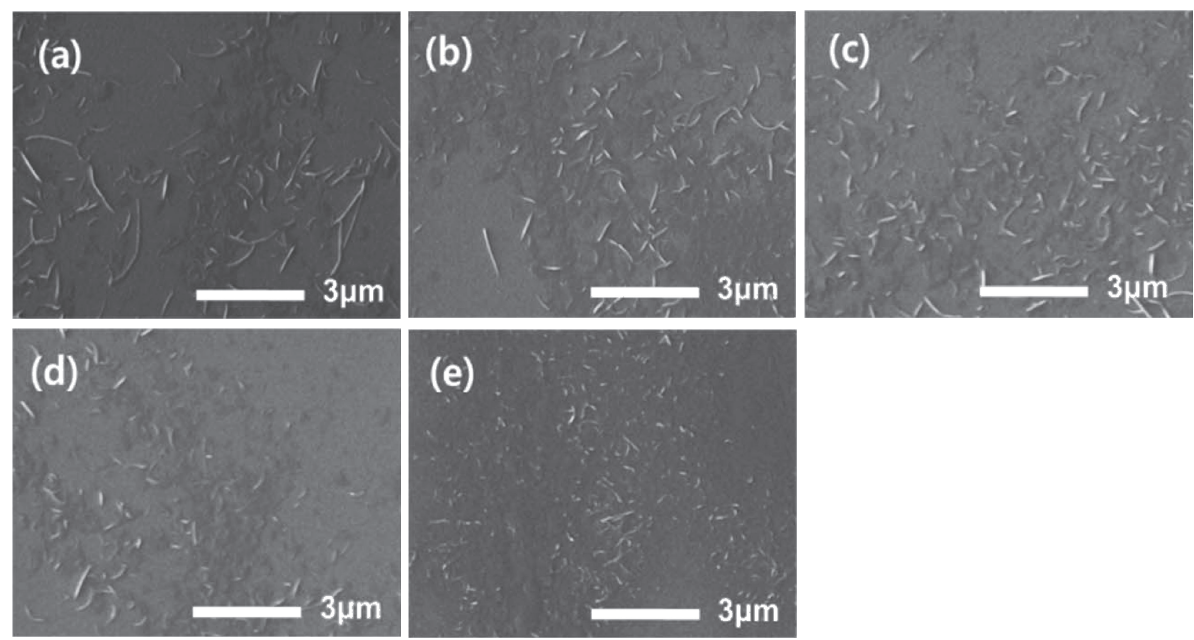

Fig. 4. SEM surface images of SWCNTs-incorporated $\mathrm{ZnO}$ films with various ball-milling time of SWCNTs: (a) before, (b) $3 \mathrm{~h}$, (c) $6 \mathrm{~h}$, (d) $9 \mathrm{~h}$, and (e) $12 \mathrm{~h}$. Before incorporated into ZnO matrix, SWCNTs were centrifuged to be purified.

light region which is enough to transparent electrode. For example, an average transmittance was $91.8 \%$ in pure $\mathrm{ZnO}$ film. By changing of milling time from 0 to $12 \mathrm{~h}$ with an interval of $3 \mathrm{~h}$, each average transmittance was $89.9,89.6,89.5,89.1$, 88.9 , and $87.8 \%$. Film thickness is about $70 \mathrm{~nm}$ as measured by ellipsometry regardless of incorporation of SWCNTs. The slight reduction of transmittance occurred with the incorporation of SWCNTs, because SWCNTs scattered the light in films. ${ }^{31)}$ Also a little decrease in transmittance in visible light region occurred as ball-milling progress because a high degree of dispersion led to a decrease in transparency. ${ }^{32)}$ The surface images of SWCNTs incorporated $\mathrm{ZnO}$ film were obtained by using SEM to check the distribution of SWCNTs in $\mathrm{ZnO}$ matrix. As shown in Fig. 4, SWCNTs were distributed well in $\mathrm{ZnO}$ matrix in all samples. The resistivity of SWCNT-incorporated $\mathrm{ZnO}$ films was measured using Hall effect measurement system to observe changes in electrical properties by addition of SWCNTs with various dispersity. The resistivity of SWCNT-incorporated $\mathrm{ZnO}$ films decreased from 1.62 to $0.53 \Omega \mathrm{cm}$ by increasing of ball-milling time until $9 \mathrm{~h}$. The reason was revealed from the SEM data why ball-milling time has effect on the dispersity of SWCNTs. As shown in Fig. 1(a), before ball-milling, the aggregates of SWCNTs are very dense and severely entangled. But after milling process SWCNTs formed fine mesh structures which related effective conductive-networks. ${ }^{27)}$ These changes can be explained why ball-milling helps enhancement of electrical conductivity in SWCNT-incorporated $\mathrm{ZnO}$ film. As a result, more uniformly dispersed SWCNTs induced an increase in the electrical conductivity of SWCNT-incorporated $\mathrm{ZnO}$ film. ${ }^{17)}$ Meanwhile after ball-milling time reached $12 \mathrm{~h}$, the resistivity of SWCNTincorporated $\mathrm{ZnO}$ film increased. It is because an aspect ratio of SWCNT became very low due to severe reduction in the length of SWCNTs as shown in Figs. 1(e) and 4(e). It has been known that SWCNT which has very low aspect ratio is needed much content to form conductive path. ${ }^{27)}$ Also it was reported that excessive ball-milling of CNT has a bad impact on the electrical property of composite due to the generation of amorphous carbon, bending, and defects. ${ }^{19)}$ In this experiment, because the amount of SWCNT was fixed, an increase of resistivity could be analyzed with the concept of conduction path. In the case of $12 \mathrm{~h}$ ball-milled sample, the resistivity was increased followed by a decreasing number of conduction paths with SWCNTs. To analyze the electrical
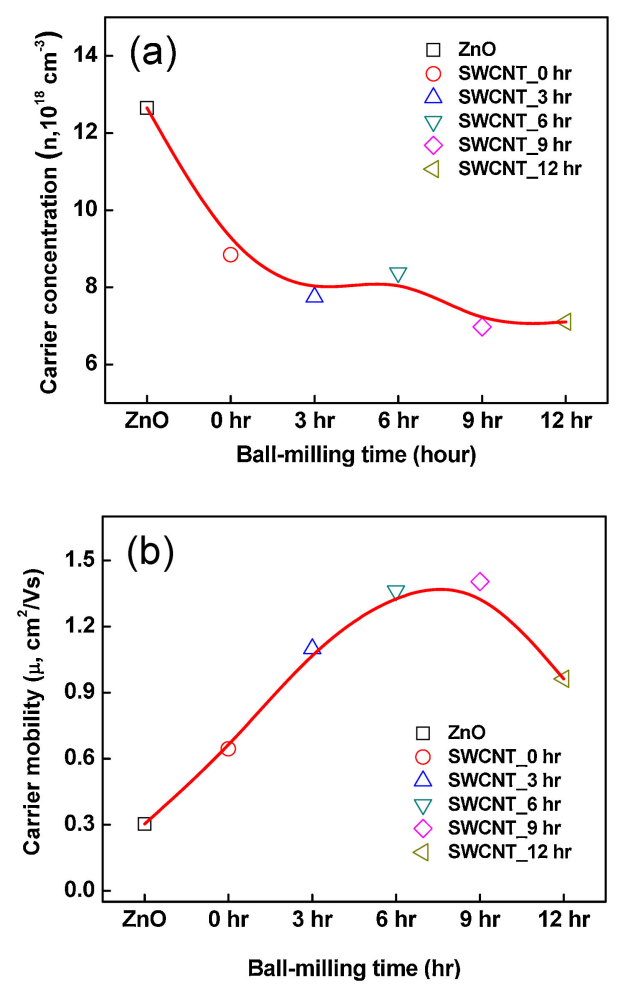

Fig. 5. (a) Carrier concentration and (b) carrier mobility of SWCNTincorporated $\mathrm{ZnO}$ thin films according to various ball-milling time.

properties of SWCNT-incorporated $\mathrm{ZnO}$ thin film with various ball-milling time, carrier concentration and carrier mobility were measured and the results were given at Fig. 5. As shown at Fig. 5, carrier concentration was decreased with SWCNT incorporation because theoretical carrier concentration of SWCNT is $10^{14}$ $\mathrm{cm}^{-3}$, this value is much smaller than the theoretical carrier concentration of $\mathrm{ZnO}{ }^{33)}$ This is why the carrier concentration of SWCNT-incorporated $\mathrm{ZnO}$ thin films was slightly decreased from pristine $\mathrm{ZnO}$ thin film and almost uniform with various ballmilling time. However carrier mobility was increased with SWCNT incorporation and ball-milling time up to $9 \mathrm{~h}$ as shown at Fig. 5(b). It was similar with the change of resistivity as shown 


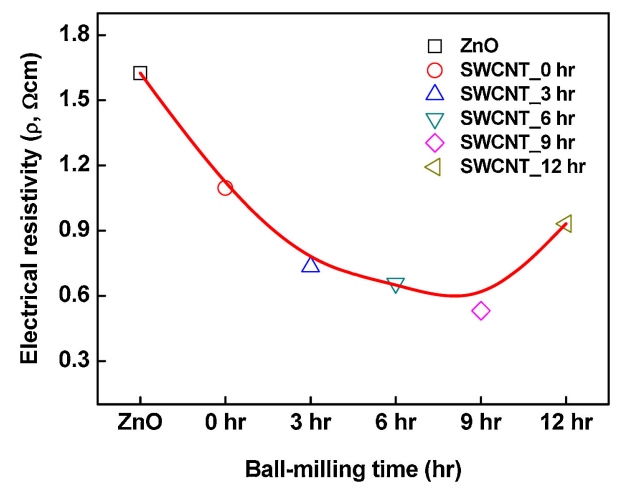

Fig. 6. Resistivity of SWCNT-incorporated $\mathrm{ZnO}$ thin films according to various ball-milling time.

in Fig. 6. The good electrical conductivity of SWCNT came from the electrical mobility with $\pi$-bond of surface. ${ }^{34)}$ By addition of SWCNT, excellent carrier mobility property induced an increase of the carrier mobility in composite and the resistivity was decreased. The carrier mobility was increased by increasing time of ball-milling up to $9 \mathrm{~h}$. It means that conducting path was obtained by good distribution of SWCNTs. The formation of effective conductive-network was affected by distribution of SWCNTs and the change of aspect ratio. However when a ballmilling time is over $12 \mathrm{~h}$, carrier transfer was inhibited due to a shortened aspect ratio which limits a formation of conductivenetwork. From these results, in order to improve the electrical property, the effective distribution of SWCNTs in matrix material was required. The formation of effective conductive-network was required with minimizing the change of aspect ratio on SWCNT to improve the electrical property of composite material.

\section{Conclusion}

Addition of well dispersed SWCNTs to ZnO did not affect significantly the crystallinity and the lattice structure of $\mathrm{ZnO}$ thin film. When dispersity of SWCNTs increased, the transmittance of $\mathrm{ZnO}$ was slightly decreased but it was enough (above 87\%) for TCO materials. Also when SWCNT was added to $\mathrm{ZnO}$, the electrical conductivity of $\mathrm{ZnO}$ increased as ball-milling time of SWCNTs was increased up to $9 \mathrm{~h}$. Because ball-milling changed aspect ratio and size of aggregates of SWCNT to form effective conductive-network. It is assumed that these formations had a relation with electron mobility on the surface of SWCNT. However a degradation of electrical conductivity of SWCNTincorporated $\mathrm{ZnO}$ thin film was obtained with $12 \mathrm{~h}$ ball-milled SWCNT due to shortened aspect ratio which limits a formation of conductive-network. In our work, the effective increasing of electrical conductivity was possible by improving dispersity of SWCNT effectively using the ball-milling.

Acknowledgements This work was supported by the National Research Foundation of Korea (NRF) Grant funded by the Korean government (MEST) (no. 2012R1A2A2A01011014). This work was supported by the third Stage of Brain Korea 21 Plus Project in 2014.

\section{References}

1) S. G. David and B. Clark, MRS Bull., 25, 15-18 (2000).

2) C. C. Wu, C. I. Wu, J. C. Sturm and A. Kahn, Appl. Phys. Lett., 70, 1348 (1997).

3) H. Kim, A. Piqué, J. S. Horwitz, H. Mattoussi, H. Murata, Z. H. Kafafi and D. B. Chrisey, Appl. Phys. Lett., 74, 3444 (1999).
4) D. H. Kim, H. R. Kim, S. H. Lee, E. S. Byon and G. H. Lee, J. Korean Inst. Surf. Eng., 42, 128-132 (2009).

5) H. Kim, C. M. Gilmore, A. Pique, J. S. Horwitz, H. Mattoussi, H. Murita, Z. H. Kafafi and D. B. Chrisey, J. Appl. Phys., 86, 6451 (1999).

6) H. Saarenpää, T. Niemi, A. Tukiainen, H. Lemmetyinen and N. Tkachenko, Sol. Energy Mater. Sol. Cells, 94, 1379-1383 (2010).

7) Y.-J. Choi, S. C. Gong, C.-S. Park, H.-S. Lee, J. G. Jang, H. J. Chang, G. Y. Yeom and H.-H. Park, ACS Appl. Mater. Interfaces., 5, 3650-3655 (2013).

8) H. Kim, M.-K. Yun and H.-H. Park, Phys. Status Solidi A, 208, 1869-1872 (2011).

9) P. F. Carcia, R. S. McLean, M. H. Reilly and G. Nunes, Jr., Appl. Phys. Lett., 82, 1117 (2003).

10) D.-J. Lee, H.-M. Kim, J.-Y. Kwon, H. Choi, S.-H. Kim and K.-B. Kim, Adv. Funct. Mater., 21, 448-455 (2011).

11) H. Serier, A. Demourgues and M. Gaudon, Inorg. Chem., 49, 6853-6858 (2010).

12) B. Sang, A. Yamada and M. Konagai, Sol. Energy Mater. Sol. Cells, 49, 19-26 (1997).

13) Y.-J. Choi and H.-H. Park, J. Mater. Chem. C., 2, 98-108 (2014).

14) J. Rousset, E. Saucedo and D. Lincot, Chem. Mater, 21, 534540 (2009)

15) H. Kim, H.-H. Park, H. Jeon, H. J. Chang, Y. Chang and H.-H. Park, Ceram. Int., 35, 131-135 (2009).

16) H. Kim, J. T. Baek and H.-H. Park, Thin Solid Films, 529, 234-237 (2013).

17) P.-C. Ma, N. A. Siddiqui, G. Marom and J.-K. Kim, Composites: Part A, 41, 1345-1367 (2010).

18) D. Simien, J. A. Fagan, W. Luo, J. F. Douglas, K. Migler and J. Obrzut, ACS Nano, 2, 1879-1884 (2008).

19) J. Hilding, E. A. Grulke, Z. G. Zhang and F. Lockwood, J.Dispersion Sci. Technol., 24, 1-41 (2003).

20) Y. Y. Huang and E. M. Terentjev, Polymers, 4, 275-295 (2012).

21) Y. B. Li, B. Q. Wei, J. Liang, Q. Yu and D. H. Wu, Carbon, 37, 493-497 (1999).

22) B. Gao, C. Bower, J. D. Lorentzen, L. Fleming, A. Kleinhammes, X. P. Tang, L. E. McNeil, Y. Wu and O. Zhou, Chem. Phys. Lett., 327, 69-75 (2000).

23) J. Y. Huang, H. Yasuda and H. Mori, Chem. Phys. Lett., 303, 130-134 (1999).

24) Y. A. Kim, T. Hayashi, Y. Fukai, M. Endo, T. Yanagisawa and M. S. Dresselhaus, Chem. Phys. Lett., 355, 279-284 (2002).

25) K. Awasthi, R. Kamalakaran, A. K. Singh and O. N. Srivastava, Int. J. Hydrogen Energy, 27, 425-432 (2002).

26) W. Bauhofer and J. Z. Kovacs, Compos. Sci. Technol., 69, 1486-1498 (2009).

27) H. Yoon, M. Yamashita, S. Ata, D. N. Futaba, T. Yamada and K. Hata, Scientific reports, 4, 3907 (2014).

28) F. Inam, M. J. Reece and T. Peijs, J. Compos. Mater., 46, 1313-1322 (2011).

29) K. Kobashi, S. Ata, T. Yamada, D. N. Futaba, M. Yumura and K. Hata, Chem. Sci., 4, 727-733 (2013).

30) Joint Committee for Powder Diffraction Studies (JCPDS) No. 36-1451.

31) A. D. Pasquier, H. E. Unalan, A. Kanwal, S. Miller and M. Chhowalla, Appl. Phys. Lett., 87, 203511 (2005).

32) S.-B. Lee, W. Lee, J.-W. Yi, B.-H. Jeong and M.-K. Um, "Relationship between dispersion and UV-visible transmittance in nanocarbons reinforced composites", 18th International conference on composite materials.

33) J. M. Marulanda and A. Srivastava, Phys. Status Solidi (b), 245, 2558-2562 (2008).

34) Q. Yan, J. Wu, G. Zhou, W. Duan and B. Gu, Phys. Rev. B, 72, 155425 (2005). 